\title{
CIEP e Programa Mais Educação: duas políticas, duas concepções de educação
}

\author{
CIEP and Mais Educação Program: two politics, two \\ conceptions of education
}

\section{Álvaro Luiz Maritan \\ alvaromaritan@gmail.com}

Graduando em Ciências Sociais - PUC-Rio

\begin{abstract}
Resumo
Este artigo compara duas políticas que implementaram a educação integral: os Centros Integrados de Educação Pública (CIEPs) e o Programa Mais Educação. As estruturas dessas duas políticas mostram mudanças de visão na maneira como a educação caminha no Brasil. Os CIEPs baseiam-se na concepção integral do ser humano, enquanto o Programa Mais Educação sintoniza-se com as demandas do mercado.

Palavras chave: Educação integral; educação em tempo integral; neoliberalismo; mercado.
\end{abstract}

\begin{abstract}
This article compare two politics: the CIEP and the Programa Mais Educação. The structures of these two politics show changes in the way education moves in Brazil. The CIEP is based on the integral conception of the human being, considering all its dimensions, while the Mais Educação Program is in tune with the demands of the market.
\end{abstract}

Keywords: integral education; full time education; neoliberalism; market. 


\section{Introdução}

O texto objetiva debater duas propostas sobre educação integral. Para tanto, consubstancia-se em análise bibliográfica e documental, assim como em entrevista com o idealizador do projeto observatório dos Centros Integrados de Educação Pública (CIEPs). Além da parte introdutória e das considerações finais, a primeira seção do texto apresenta uma breve contextualização sobre os fatores que estruturam a construção de uma política pública. A segunda discute a concepção que norteou a criação dos CIEPs. A terceira aborda o Programa Mais Educação e a quarta seção procura pontos de contato e distanciamento entre as duas políticas educacionais. Ao mostrar essa influência, o texto procura refletir em que medida o setor privado atuou no Programa Mais Educação dando-lhe mais sintonia com o mundo do mercado.

\section{Breve contextualização das políticas}

Inicialmente, cabe discutir os motivos pelos quais determinados temas são objetos de políticas públicas. Capella (2007) questiona por que certas ideias viram políticas públicas, ou seja, por que algumas questões são consideradas problemas para a sociedade a ponto de exigir uma ação governamental. A educação integral é um desses problemas eleitos para a elaboração de uma política pública demandando uma intervenção do Estado por meio de ações governamentais. Os Centros Integrados de Educação Pública (CIEPs) foram arquitetados tendo como base uma proposta pedagógica inovadora em um contexto em que a ideia de direitos estava fortalecida na sociedade brasileira.

De acordo com Bonemy (2009), Darcy Ribeiro era apaixonado pelo Brasil, mas lamentava o fato de o país pagar um preço alto pelo egoísmo das elites que não se importam com o povo. A reação contrária aos CIEPs reforça tal concepção, já que a política educacional foi duramente criticada. Durante a ditadura militar não houve investimentos na educação pública. Segundo Pinto (2014), ditaduras não gostam de educação, visto que o governo militar tirou a vinculação dos recursos para a educação. No contexto de redemocratização, Darcy investiu em aspectos da educação que os governos militares não deram importância. Seu sonho era que os CIEPs fossem uma escola universal que também incluísse a classe média.

O Programa Mais Educação foi uma ação dirigida pelo governo federal visando melhorar a qualidade da educação na escola pública brasileira. Tal ação integra o Plano de Desenvolvimento da Educação (PDE), considerado pelo ex-presidente Lula, o Plano de 


\section{DIGNIDADE}

Aceleração do Crescimento da Educação. O Programa Mais Educação é uma das ações do PDE. O Decreto nº 6094/2007 dispõe sobre o Plano de Metas Compromisso Todos Pela Educação e sobre o lançamento do PDE. O PDE foi apresentado à sociedade brasileira como um plano de ação e resposta institucional ao desafio de melhora da qualidade do ensino (BRASIL, 2007).

O Programa Mais Educação foi instituído pela Portaria Interministerial n ${ }^{\circ} 17$ em 24 de abril de 2007, fundamentado no artigo 34 e artigo 87, parágrafo $5^{\circ}$ da Lei de Diretrizes e Bases da Educação Nacional (BRASIL,1996) e foi regulamentado com objetivo de induzir a educação integral, procurando melhorar a qualidade do ensino.

Art. 34. A jornada escolar no ensino fundamental incluirá pelo menos quatro horas de trabalho efetivo em sala de aula, sendo progressivamente ampliado o período de permanência na escola.

Art. 87. É instituída a Década da Educação, a iniciar-se um ano a partir da publicação desta Lei.

$\S 5^{\circ}$ Serão conjugados todos os esforços objetivando a progressão das redes escolares públicas urbanas de ensino fundamental para o regime de escolas de tempo integral (BRASIL, 1966).

Para debater essas duas políticas educacionais é necessário considerar o contexto histórico da ideia de uma educação em tempo integral. É importante entender como se construiu a relação entre sociedade e Estado no Brasil. Santos (1993) diz que o Brasil é um país dotado de particularidades, considerando que na formação do Estado brasileiro há uma baixa participação política da sociedade.

No sistema político construído na Proclamação da República a participação eleitoral era restrita. O Estado republicano autoritário era similar ao de Hobbes, com o Leviatã, perseguindo quem ameaçava seu poder. Este sistema formou-se sem a participação do povo. Durante o breve intervalo democrático entre 1946 e o golpe militar de 1964, houve resistências à criação de conselhos que permitem a participação da sociedade na execução e no controle de políticas públicas. Depois da queda do muro de Berlim, a democracia representativa se tornou um valor universal, influenciando a redemocratização da sociedade brasileira. Porém, há diferenças entre o modo como ela é vivida em países europeus, tais como França e Itália, e na América Latina. Para Santos (1993) "essa consideração é de suma relevância porque identifica a origem da instabilidade recorrente dos sistemas latino-americanos em uma peculiaridade no seu processo de formação".

Com políticas de cunho neoliberal, de acordo com Santos (1993), o Partido dos Trabalhadores tentou replicar a social democracia. A observação do autor reforça a crítica de Darcy Ribeiro às elites. Os CIEPs foram implantados num contexto em que uma parcela da 
sociedade negava o autoritarismo da ditadura militar, de modo que uma parte da sociedade brasileira se mobilizou na luta pela redemocratização. Podemos questionar até que ponto características do Leviatã, tal como Wanderley dos Santos descreveu, são válidas naquele contexto de organização da sociedade.

Nos anos de 1980, renasceu a ideia da educação como solução para superar a desigualdade. A Constituição Federal promulgada em 1988 é fruto de uma conjuntura que reconheceu a educação como um direito do cidadão e consignou a gestão democrática como um princípio constitucional. Nesse cenário, a escola deve ser um espaço democrático, que fomente a participação da sociedade. Assim, a ideia de uma educação em tempo integral foi fortalecida por atores como Darcy Ribeiro e Brizola, voltando a ganhar destaque com o Programa Mais Educação.

\section{Os Centros Integrados de Educação Pública}

Os Centros Integrados de Educação Pública (CIEPs) tornaram-se referência para qualquer discussão sobre escola em tempo integral. Idealizados por Darcy Ribeiro e prédios projetados por Oscar Niemayer, foram construídos 506 CIEPs no estado do Rio de Janeiro durante dois governos de Leonel Brizola (1983-1987 e 1991-1994). A localização geográfica das construções tinha como referência as populações mais carentes (MORGAN,2015).

O objetivo dos CIEPs era integrar na escola aspectos como saúde, cultura, atendimento dentário, suporte psicológico e familiar. Os prédios foram construídos de forma uniforme e funcionavam em atendimento a turno único das 8 às 17 horas. Cada CIEP comportava 1000 alunos e seu projeto arquitetônico se dividia em três blocos. No bloco principal, localizavamse as salas de aula, cozinha, refeitório, secretaria, direção, salas de apoio, recreação e um centro médico. No segundo bloco, a quadra poliesportiva. E no terceiro, a moradia dos alunos residentes (MORGAN, 2015).

Estes alunos eram crianças e adolescentes em situação de risco. A estadia era temporária, e deveria ocorrer um trabalho de assistência social para reinserção do aluno na família. O objetivo era impedir a evasão escolar e, por meio da convivência, intervir sobre o problema social. Relembrar essa política torna-se importante quando é noticiado que, devido à superlotação de unidades socioeducativas, o estado do Rio de Janeiro dará liberdade a menores infratores que tenham sido apreendidos por crimes considerados de menor gravidade. Em entrevista à Rede Globo, a juíza Lúcia Glioche, titular da Vara de Execução de Medidas 
Socioeducativas, informou que os menores infratores deverão ter amparo familiar. Se o adolescente não contar com a família é “impossível qualquer tentativa de ressocialização fora da unidade" (DOLZAN, 2019). Tal fato confirma frase de Darcy Ribeiro proferida em conferência no ano de 1982: "se os governantes não construírem escolas, em 20 anos faltará dinheiro para construir presídios" (cf. DOLZAN, 2019).

A crítica ao CIEP centrou-se no caráter assistencialista do projeto. $\mathrm{O}$ fornecimento de 3 a 4 refeições por dia, o atendimento médico-odontológico, os alunos residentes e a instituição de caixa escolar para o fornecimento de uniforme e calçado àqueles que não possuíssem condições econômicas de adquiri-los, foram ingrediente que fomentaram a discussão sobre o aspecto assistencialista. Morgan (2015) sinaliza que autores como Vitor Henrique Paro cobravam garantia para o "ensino de boa qualidade em período parcial - o que está muito longe de acontecer - para depois falar-se em extensão da escolaridade para período integral". Os defensores dos CIEPs defendiam a necessidade da resolução do problema de crianças vulneráveis. Essas estariam na escola durante o dia e sairiam das ruas. Para Ribeiro (1986) os CIEPs tiram os jovens do crime. "É inviável educar crianças desnutridas. Então o CIEP supre as necessidades alimentares dos seus alunos. A maioria dos pais não tem recursos financeiros. Então o CIEP fornece gratuitamente material". Da mesma forma, defende que o CIEP proporcione assistência médica e odontológica aos alunos expostos a doenças infecciosas, problemas dentários ou deficiência visual ou auditiva (MORGAN, 2015).

Ressalta-se que o argumento contrário aos CIEPs mostra a dificuldade da elite brasileira de aceitar políticas públicas que combatam a desigualdade. O projeto teve como objetivo atenuar a desigualdade na sociedade brasileira oferecendo uma educação de qualidade tanto para os pobres quanto para a classe média. Porém, como sinalizaram Wanderley Santos e Darcy Ribeiro, a elite brasileira é egoísta, logo as políticas públicas que combatam a desigualdade nunca serão suficientes, pois compreende os problemas que a política naturalmente não resolve. Em outras palavras, uma política publica nunca dá conta de resolver os problemas como um todo. O argumento da elite é uma falácia.

Tanto Darcy Ribeiro quanto o governador do estado do Rio de Janeiro à época, Leonel Brizola, foram importantes atores para a implementação de escolas em horário integral no Rio de Janeiro. Ambos ficaram sensibilizados com os problemas externos dos alunos da escola pública - dentários, visuais, entre outros. O CIEP seria uma solução a esses problemas, pois a maneira como a política pública foi implementada permitia isso (MORGAN, 2015).

Os CIEPs buscavam transformação. A escola integral buscava atender também os carentes, indisciplinados e violentos. O objetivo era integrar diversas dimensões da vida do DIGNIDADE RE-VISTA | ISSN2525-698X| 2018 | V. IV | N. 8 | Políticas Públicas e Direitos Humanos. 
aluno, a escola não devia centrar-se apenas no currículo. Tentava transformá-los em "pessoas capazes de integrar a sociedade" (CAVALIERE, 2009). A partir da experiência em educação integral realizada por Darcy Ribeiro nos governos de Leonel Brizola, cresceu a discussão acerca da educação em tempo integral, materializada em outra política, no Programa Mais Educação. A escola ganhou novos espaços, indo para clubes, parques, cinemas etc. Nesse sentido, o Programa Mais Educação tem alguns pontos de contato com o projeto dos CIEPs.

\title{
A Educação Integral no Programa Mais Educação
}

Ao estudar as políticas públicas, percebe-se que elas são feitas por diferentes atores em diferentes conjunturas. Enquanto os CIEPs foram criados no contexto de redemocratização, num ambiente de relativa mobilização de parcela da sociedade, o Programa Mais Educação foi concebido numa conjuntura em que as ideias neoliberais conquistavam hegemonia em parte do mundo. Nesse cenário, a escola ampliou suas funções.

\begin{abstract}
No atual cenário de hegemonia neoliberal, a ampliação das funções da escola, incorporando tarefas de proteção social, é uma expressão do aprofundamento da redução das políticas sociais que transformam a escola pública elementar brasileira em uma espécie de posto avançado do Estado, utilizada para garantir certas condições de controle populacional e territorial, formas variadas de negociação do poder em diferentes escalas e certa economia de presença em outros âmbitos da vida social. (SILVA; SILVA,2013, p.706)
\end{abstract}

De acordo com Cavaliere (2009), há dois modos de conceber a educação em tempo integral, uma forma da educação está a serviço do mercado, enquanto outra visa uma formação ampla do ser humano.

O Programa Mais Educação apresentava uma visão focada no mercado, haja vista que ações do Programa do Desenvolvimento Educação (PDE) foram elaboradas e executadas com o apoio de grandes grupos empresariais como a Fundação Itaú, Fundação Bradesco, Fundação Roberto Marinho, Fundação Ayrton Senna entre outros, revelando a lógica neoliberal do programa (SILVA; SILVA, 2013). Os governos federal, estadual e municipal desenvolveram ações do PDE, dentre eles o Programa Mais Educação (PME), que transfere dinheiro para municípios e estados cumprirem metas que são definidas pelo governo federal como, por exemplo, o diálogo entre a escola, a família e o cumprimento de funções que pertenciam ao Estado. 
Os intelectuais dos governos do Partido dos Trabalhadores tinham a intenção de combater a desigualdade sem questionar as bases materiais que as legitimam, mostrando a contradição de um partido de esquerda. A mudança no papel da escola ocorre justamente quando o capitalismo revela sua face mais cruel, mostrando que esse sistema não tem como garantir vida digna para todos (SILVA; SILVA, 2013).

O Programa Mais Educação mostra uma tentativa de disciplinar a pobreza e não questiona as injustiças do sistema capitalista. Para entender os programas de educação integral depois dos CIEPs, e a maneira pela qual caminha a educação pública no presente, é importante entender o fenômeno do neoliberalismo que se distingue do liberalismo clássico. O neoliberalismo ataca qualquer tipo de intervenção que o mercado sofra. Suas ideias tiveram inspiração no livro $O$ caminho da servidão de Friedrich Hayek. De acordo com o pensamento neoliberal, a ideia de um Estado interventor seria uma ameaça não apenas à liberdade econômica, mas também à liberdade política. Essas ideias, no início, não foram ouvidas, mas com a crise do capitalismo, em 1973, ganharam força. Hayek e seus seguidores culparam os sindicatos, o movimento operário e os gastos sociais do Estado pela crise. O foco do neoliberalismo é o sucesso do mercado, questões como a redução das desigualdades não são importantes (ANDERSON,1995).

O Programa Mais Educação tentou construir uma aliança do poder público com empresas privadas em setores da saúde, educação e esportes. A reforma do Estado brasileiro iniciou no governo Fernando Henrique, mas em áreas essenciais, como saúde e educação, as empresas privadas tinham que ter objetivos não lucrativos, ou seja, se tais empresas não fossem estatais elas não poderiam ter fins lucrativos, funcionando como ONGs. No governo do ex-presidente Lula, houve o aprofundamento da reforma neoliberal e tal exigência deixou de existir. Isso mostra que dentro do governo petista também aconteceu um aprofundamento do neoliberalismo. No contexto das ideias neoliberais, o mercado prevalece sobre as necessidades das pessoas, com reflexos e mudanças da educação (DI PIETRO, 2015).

Há entre o Estado e o mercado o compartilhamento de benefícios econômicos por meio de parcerias entre o público e o privado provocando endividamento dos governos. Nessa relação o interesse público não é priorizado, pois como o mercado está interessado em aumentar o capital, o público enfraquece. O foco do liberalismo clássico são os direitos do homem e do cidadão, enquanto o neoliberalismo tem como base a liberdade do mercado, ou seja, a liberdade do homem enquanto um consumidor e não como um cidadão portador de direitos (MARRACACH, 1996). 


\section{Políticas educacionais e concepções de mundo}

Os CIEPs foram criados no contexto em que a ideia de direitos humanos estava fortalecida, incluindo o direito à educação. Autores marxistas elaboraram uma pedagogia socialista que deveria ser pública, laica e livre das influências da religião, do Estado e das classes. Conforme essa concepção, a educação é responsável pela formação política dos cidadãos, aproximando tal pedagogia da idealização dos CIEPs. A escola legitima as relações de produção, ideologia e o Estado presentes na estrutura social. Assim, nos modelos de educação existentes em nossa sociedade surgem diferentes pedagogias que expressam diferentes projetos de sociedade. A pedagogia marxista compreende que a aprendizagem não deve ter como objetivo a passividade do aluno e nem a aprendizagem por meios mecânicos, visto que o caminho para o socialismo requer uma educação crítica e integral do ser humano.

Ao falar do papel da escola na sociedade contemporânea, a Sociologia da Educação mostra que todas as sociedades têm uma maneira de transmitir o conhecimento das gerações mais novas para as mais velhas. Conforme Brandão (2017), em todas as sociedades há transferência dos saberes de uma geração para outra. A noção de educação como percebemos hoje surge com a invenção da infância na sociedade capitalista. Nas sociedades anteriores às capitalistas, as crianças já nasciam com uma profissão definida, que aprendiam com os pais. Não havia separação entre educação escolar e trabalho. Na sociedade capitalista há uma transferência do poder obtido pela propriedade, passando pelo capital escolar (SINGLY,2008). Tal mudança na transferência mostra como a educação é importante na manutenção do poder das classes dominantes.

Foi mencionado anteriormente o contexto histórico do CIEP, mobilizado pela parcela da sociedade que, nos anos 1980, lutou pela redemocratização. A Constituição Federal (BRASIL, 1988) foi inspirada na declaração dos direitos do homem que surgiu depois de regimes ditatoriais como o stalinismo, fascismo e o nazismo. Daquele contexto emergiu a ideia dos direitos humanos para proteger o ser humano do autoritarismo do Estado e do mercado. $\mathrm{O}$ Estado de bem-estar social é criado se contrapondo à ideia de um Estado mínimo.

A Constituição Federal é um avanço dos direitos, pois teve como base as declarações dos direitos humanos que considera a educação um direito social. Pela primeira vez na História do Brasil uma Constituição se comprometeu com o fim da pobreza e com a redução de desigualdades. A ideia da proteção do indivíduo contra um Estado autoritário era forte, ao mesmo temo que tentava proteger o indivíduo dos males do mercado. A Constituição Federal 
tentou ser um contraponto à experiência vivida na ditadura militar, por isso propôs dispositivos que protegem os indivíduos, asseguram direitos e requerem uma ação dos Estados para a promoção de uma educação pública de qualidade e democrática (ROCHA, 1998).

No entanto, a ideologia neoliberal foi ganhando espaço e o Estado começou a ser criticado e apontado como responsável pelas mazelas do país. O neoliberalismo se apresenta com um anticomunismo intransigente. Os Estados Unidos, na época da Guerra Fria, usaram do neoliberalismo para enfrentar o comunismo na URSS. Aos poucos, conforme a ideologia neoliberal foi se expandindo, o Estado de bem-estar social foi se descontruindo. Nessa expansão, governos que se autoproclamavam de esquerda adotavam medidas neoliberais. $\mathrm{O}$ neoliberalismo considera o desemprego importante para que a economia de mercado funcione. Várias sociedades não capitalistas valorizaram o mercado, porém é no capitalismo que ele ganha uma força única. Marx descreveu o fenômeno que denominou fetichismo da mercadoria, específico da sociedade capitalista, que fala de um processo em que as pessoas viram mercadoria. Tal princípio é posto em prática quando o neoliberalismo recomenda uma taxa de desemprego. Desse modo o sucesso do mercado está acima da dignidade de vida dos seres humanos (ANDERSON,1995).

As ideias neoliberais vão contra as de um Estado providência, que o texto da Constituição Federal valorizou e implica direitos universais aos seres humanos, independentemente da lógica do mercado. Muitos partidos de esquerda não governaram de maneira diferente dos seus adversários liberais. Dentre as práticas neoliberais está o desmonte dos serviços públicos, a privatização. Anderson (1995) destaca que a primeira experiência neoliberal foi no Chile de Pinochet, causando um grande índice de desemprego, repressão dos sindicatos e benefício aos mais ricos. O neoliberalismo se espalhou de maneira global, de forma semelhante ao que Marx descreveu no Manifesto Comunista. Assim, criou sociedades mais desiguais, porém nem tanto menos estatizantes do que pretendia. Defendeu que a liberdade do mercado iria mudar o capital dos países ricos para os pobres, o que não ocorreu na realidade.

Políticas públicas como o Programa Mais Educação contaram com a participação de empresas privadas, expressando sintonia com o neoliberalismo. Essa dinâmica não é vista nos CIEPs. As diferenças começam na denominação: educação integral e educação em tempo integral. Os CIEPs não tinham vínculos com empresas e visavam uma educação pública de qualidade e a redução da desigualdade.

Segundo Bresser-pereira (2007), a construção de um Estado neoliberal começou no governo Collor. O autor reforça a importância da propriedade pública não estatal nas sociedades contemporâneas. No entanto, destaca que serviços como saúde e educação envolvem DIGNIDADE RE-VISTA | ISSN2525-698X| 2018 | V. IV | N. 8 | Políticas Públicas e Direitos Humanos. 
externalidades positivas e são importantes para que o Brasil cumpra uma agenda de direitos humanos, pois caso tais atividades estejam sob o domínio do mercado, serão administradas visando o lucro. Caracterizou o momento histórico do Brasil, entre 1930 e 1984, importante no processo de industrialização, marcado pelo autoritarismo e o nacional desenvolvimentismo. Diferente do momento em que foi ministro do governo Fernando Henrique Cardoso, caracterizado como um período democrático em que o neoliberalismo predominou. Percebe-se na leitura do texto uma tentativa de minimizar o poder do Estado, restringindo atuação a serviços essenciais, como saúde e educação. Tais serviços podiam ser feitos em organizações que não gastassem dinheiro com funcionários públicos. Para Bresser-Pereira (2007), o nacional desenvolvimentismo precisa ser superado. Além disso, reflete que as universidades brasileiras são um fracasso por serem do Estado, considerando como modelo de universidade os Estados Unidos e não países como a França ou Alemanha, onde estas são estatais. No governo Lula há um hibridismo, pois ocorre tanto um aprofundamento da reforma do Estado neoliberal feita pelo governo Fernando Henrique, quanto medidas que fortalecem o Estado por meio de políticas públicas.

O neoliberalismo surge em um contexto de crise da ideia de solidariedade, diferente do liberalismo clássico e conservador. A liberdade defendida se limita à liberdade do mercado. Essa concepção minimiza a educação como um direito, passando a um serviço que pode ser considerado uma mercadoria. Para o liberalismo clássico entre os quais enquadram-se pensadores como Adam Smith e Locke, a educação era uma parte dos direitos do homem e do cidadão, era um direito do ser humano (MARRACACH, 1996).

A escola, na atualidade, vê o aluno como um cliente. Direitos trabalhistas e reinvindicações para melhores condições de vida passam a ser considerados obstáculos para o crescimento econômico. De acordo com a lógica neoliberal, áreas de ciências humanas, como Sociologia e Filosofia, não são tão importantes quanto às técnicas, por isso mesmo são desvalorizadas. Na educação neoliberal a lógica da escola funde-se com a lógica empresarial. Esses processos de transformação do capitalismo fazem parte do que Weber chamou de desencantamento do mundo e Marx chama de fetichismo da mercadoria, em que tudo vira valor de mercado. O resultado do aprofundamento das políticas neoliberais é o crescimento de desempregados, moradores de rua e da desigualdade social.

Como é possível a existência de uma educação de qualidade para todos, tendo como base a expansão das ideias neoliberais? Deve-se perguntar quais seres humanos e qual projeto de sociedade se pretende produzir. Segundo Franco, Alves e Bonamino (2007), para que a escola seja de qualidade é preciso que sejam articulados fatores inter e intraescolares, deve-se refletir 
sobre a educação de qualidade problematizando quais seres humanos e sociedade se pretende formar. Para os autores, uma educação de qualidade deve discutir questões como fome, drogas, violência, sexualidade, família, raça entre outros, de modo que todas as dimensões da vida do aluno sejam integradas pela escola.

A escola deve dar aos seus alunos igualdade de condições. Pode ser integral ou parcial, mas precisa garantir o livro didático, livros de literatura, merenda, transporte e cultura, os elementos integrantes do processo educativo. Destaca-se também a importância de laboratórios de informática e espaço com brinquedos para a educação infantil. A escola que deseja ser de qualidade deve ter cuidado e respeito à heterogeneidade do seu público, não se deve excluir alunos considerados fracassados ou lentos. Essa inclusão muitas vezes é um obstáculo para a educação que prioriza as necessidades do mercado.

\section{Considerações finais}

O artigo discutiu duas políticas públicas: os Centros Integrados de Educação Pública e o Programa Mais Educação. Abordou-se a relação entre sociedade e o Estado no Brasil concluindo que na história brasileira há pouca participação da sociedade. O contexto histórico que culminou na criação dos CIEPs foi marcado pela mobilização de parcela da sociedade que lutou pela redemocratização do país, em que os ideais da democracia representativa se tornaram valores universais. No cenário de mobilização, a Constituição Federal expressou um Estado de bem-estar social em que os direitos humanos foram valorizados, ou seja, valorizou-se a ideia de que o ser humano tem direitos independente de sua classe social.

A partir da década de 1990, ocorre uma expansão do neoliberalismo até mesmo em governos de esquerda, como foi o caso dos governos do Partido dos Trabalhadores, mostrando suas contradições. A ideia de uma educação integral foi destaque no estado do Rio de Janeiro com a construção de 506 CIEPs, voltando à cena da política por meio do Programa Mais Educação do governo federal. Há pontos de contato entre os dois programas: ambos atendem a população mais vulnerável, há atividade extraclasse, mas apresentam um ponto de distanciamento relevante, tendo em vista que retratam diferentes contextos históricos.

O Programa Mais Educação teve apoio de grupos empresariais como a fundação Roberto Marinho, Fundação Unibanco, Fundação Ayrton Senna, entre outros. Esta associação da educação com os empresários, não está em sintonia com a concepção de educação que consubstanciou a construção dos CIEPs. 
A ideia de uma educação de qualidade precisa contemplar todos os aspectos da vida de um aluno. Deve abordar assuntos como sexualidade e raça, e não uma educação que aborde apenas os conteúdos tradicionais. Os CIEPs tinham a preocupação de integrar as dimensões da vida do aluno e não apenas a preocupação de prepará-los para o mercado de trabalho. Com a expansão das ideias neoliberais, emergem os antagonismos do sistema capitalista, por isso essa reflexão é importante. Afinal, a educação irá se preocupar apenas com as necessidades do mercado ou promover uma educação ampla e acolhedora, se preocupando com o aluno, considerando os vários aspectos de sua vida?

\section{Referências bibliográficas}

BOMENY, Helena. A escola no Brasil de Darcy Ribeiro. Em Aberto, v.21 n.80, 2009.

BRANDÃO, Carlos Rodrigues. O que é educação? São Paulo: Brasiliense, 2017.

BRASIL. Constituição da República Federativa do Brasil, 1988. Diário Oficial [da] União da República Federativa do Brasil. Brasília, 5 out 1988.

BRASIL. Decreto $n^{\circ}$ 6.094, de 24 de abril de 2007. Dispõe sobre a implementação do plano de metas compromisso todos pela educação, pela União Federal, em regime de colaboração 
com Municípios, Distrito Federal e Estados, e a participação das famílias e da comunidade, mediante programas e ações de assistência técnica e financeira, visando a mobilização social pela melhoria da qualidade da educação básica. Diário Oficial [da] União da República Federativa do Brasil. Brasília, 25 abr 2007.

BRASIL. Lei $n^{\circ}$ 9.394, de 20 de dezembro de 1996. Estabelece as Diretrizes e Bases da Educação Nacional. Diário Oficial [da] União da República Federativa do Brasil. Brasília, 23 dez 1996.

CAPELLA, Ana Maria. Perspectivas teóricas sobre o processo de formulação de políticas públicas. In: HOCHMAN, G. et al. (org.). Políticas Públicas no Brasil. Rio de Janeiro: Fiocruz, 2007, p.87-122.

CAVALIERE, Ana Maria. Escolas de tempo integral versus alunos em tempo integral. Em aberto, v.21 n.80, 2009.

DI PIETRO, Maria Sylvia Zanella. Parcerias na Administração Pública. São Paulo: Atlas, 2015.

DOURADO, Luiz Fernandes; OLIVEIRA, João Ferreira de. A qualidade da educação: perspectivas e desafios. Cadernos Cedes, v.29, n.78, , 2009.

DOLZAN. Marcio. Por superlotação, Rio terá de liberar ou transferir menores infratores. Jornal O Estado de São Paulo. São Paulo, 1 jun 2019.

FRANCO, Creso; ALVES, Fátima; BONAMINO, Alicia. Qualidade do ensino fundamental: políticas, suas possibilidades, seus limites. Educação \& Sociedade. v.28 n.100, 2007.

LOMBARDI, José Claudinei; SAVIANI, Dermeval. Marxismo e educação: debates contemporâneos. Campinas: Autores Associados, 2005.

MARRACH, Sonia Alem et al. Neoliberalismo e educação. Infância, educação e neoliberalismo. São Paulo: Cortez, 1996.

MORGAN Karine Vichiett. O Programa Mais Educação no Formigueiro das Américas: a política de indução à educação integral no município de São João de Meriti. Dissertação apresentada ao Programa de Pós-Graduação em Educação da Universidade Federal Fluminense, como requisito parcial para obtenção do grau de mestre em educação. 2015.

PEREIRA, Bresser. Burocracia pública e reforma gerencial. Revista do Serviço Público, Brasília, ENAP, p.29-48, 2007.

Perry Anderson. Balanço do neoliberalismo. Pós neoliberalismo. Rio de Janeiro: Paz e Terra, 1995.

PINTO José Marcelino de Rezende. O Golpe de 1964 e o financiamento: ditaduras não gostam de educação. Revista Brasileira de Política e Administração da Educação (ANPAE), Goiânia, v.30, n.2, 2014.

RIBEIRO. Darcy. O livro dos CIEPs. Rio de Janeiro: Bloch, 1986. 
ROCHA, Fernando Luiz Ximenes. Direitos Fundamentais na Constituição de 88. Themis: Revista da Esmec, v.1, n.2, p.109-123, 2016.

SANTOS, Wanderley Guilherme. Razões da Desordem. Rio de Janeiro: Editora Campus, 1987.

SILVA, Jamerson Antonio de Almeida; SILVA, Katharine Ninive Pinto. A hegemonia às avessas no Programa Mais Educação. Revista Brasileira de Estudos Pedagógicos, v.9494, n.238, 2013.

SINGLY, François de; PEIXOTO, Clarice Ehlers. Sociologia da família contemporânea. Trad. Clarice Ehlers Peixoto, São Paulo: Editora FGV, 2008. 